\title{
“Oh dear, should I really be saying that on here?” Issues of identity and authority in an online diabetes community.
}

\begin{abstract}
We explore peer-to-peer discussions which took place in a UK-based diabetes 'Virtual Clinic' online community. In particular, we seek to understand the rhetorical nature and content of exchanges over a period of six months from the community's inception. Data were captured weekly and analysis based on thematic discourse analysis. Two key issues emerged regarding how the community shaped the nature of the discussion forum. First, the identity of the forum was established, and boundaries drawn about what was, and was not, acceptable. Second, participants sought to present themselves as reliable and authoritative sources of information. Internet discussion communities are shaped in important ways early on by the community of users, including how the character and focus of discussion is formed, and how both information and users can be constructed as authoritative and reliable.
\end{abstract}

Keywords: ehealth; diabetes; internet; discourse; 


\section{Introduction}

The promise, or at least the rhetoric, of self-management by increasingly 'expert' patients has obvious attractions for health services needing to make cost-savings in the face of ageing populations living longer with chronic disease (Holman \& Lorig, 2004; Department of Health, 2007). Self-management programmes generally aim to support healthy living by improving self-efficacy and health knowledge (Pearson et al., 2007). Diabetes is an area which has seen a plethora of initiatives in recent years and there is evidence that self-management can reduce long-term complications (Brownson et al., 2009). Diabetes is a chronic and debilitating disease characterised by an inability to regulate blood glucose levels adequately and its prevalence is rising rapidly. There are 2.8 million people currently diagnosed with diabetes in the UK (Diabetes UK, 2011). Day-to-day management is carried out almost exclusively by the patient and can often be complex and emotionally challenging, meaning that many do not achieve good control over their blood glucose levels. For patients to be effective self-managers of their diabetes they need to be provided with the information and support necessary to make informed decisions.

Interventions based on new technologies have the potential to support individuals to effectively manage their diabetes over a lifetime (Chen \& Li, 2009). Technological innovations include interactive websites, automated telephone calls, touchscreen kiosks, mobile devices and DVDs (Piette, 2007), but have mixed results (Welch \& Shayne, 2006; Costa et al., 2009). Initiatives that mobilize and build on online peer support have been described as a particularly promising way to improve selfmanagement support (Heisler, 2010). For example, anonymous internet-based information exchange and interaction with other patients has been shown to be a key strategy providing autonomy and a feeling of control for young women with diabetes managing life transitions (Rasmussen et al., 2007), and posting messages in online 


\section{1}

forums has been shown to bring benefits relating to social support, information exchange and sharing of experience for adolescents (Ravert et al., 2004).

In recent years the internet has become an increasingly important resource for health consumers. A 2009 survey found that 70 per cent of United Kingdom households now have internet access (over 18 million households), and 42 per cent of internet users have used the internet for health information within the last three months, a significant increase from 34\% in 2008 (Office of National Statistics). Similarly, a survey conducted in 2009 found that 74 per cent of United States adults use the internet, and 83 per cent of internet users have used the internet for health information (Pew Internet and American Life Project, 2010). Perceptions of the internet as a source of health information appear to be changing. A survey of ehealth trends in seven European countries found that in 2005 6.5\% of the population perceived the internet as an important source of health information, whereas by 2007 this figure had risen to $46.8 \%$ (Kummervold, 2008).

As health-related internet use has grown, the sociological literature has considered whether the informed e-consumer presents a challenge to professional dominance (Hardey, 1999) or whether online health information continues to support a model of biomedical authority (Fox et al., 2005; Nettleton et al., 2005). Research on peer-to peer interaction in virtual communities suggests that these too can reinforce mainstream discourses of medical knowledge (Fox et al., 2005; Sandaunet, 2008). At the same time, they can address issues not dealt with (or at least not to individuals' satisfaction) in traditional settings (Sandaunet, 2008; Schaffer et al., 2008). 
The emergent body of literature on online health communities in general supports a model of 'empowerment within limits' where the individual user has the opportunity to feel more competent or in control through the peer-led exchange of information and emotionally supportive messages, within the cultural constraints of the particular community being accessed. Empowerment comes from information exchange (Fox et al., 2005; Coulson, 2005), emotional and social support (Bar-Lev, 2008), access to others in similar situations (Schaffer et al., 2008; Powell \& Clarke, 2006), and other factors which facilitate user empowerment such as feelings of control and autonomy (van Uden-Kraan et al., 2009; Lemire et al., 2008). Through the sharing of experiential information, users can re-shape ideas of authoritative knowledge (Schaffer et al., 2008) and construct online identities as expert patients (Fox \& Ward, 2006).

Online communities are not without their problems, though. For example, in addition to these positive outcomes, studies of computer-mediated communication have also often commented on the phenomenon of online hostilities of variable intensity such as disagreements, criticism or aggressive emotional outbursts (Burnett and Buerkle, 2004) that can potentially cause stress and anxiety both for the interactants involved and other community members. If the potential benefits of online communities are to be most effectively harnessed then it is important to understand how they develop from the very early stages as the community's character is likely to be established relatively quickly and may then prove difficult to change. Understanding the processes through which a community's character develops highlights useful lessons that those setting up, or moderating, such communities could learn from as they seek to ensure they are as effective as possible at promoting information-sharing and supporting users to feel confident in their ability to manage their condition. 


\section{1}

The vast majority of studies analysing peer-to-peer discussion fora have focused on publicly accessible websites, and have taken an opportunistic sample of online communication over a set period. This approach can be found in many contexts for both common conditions including diabetes (Ravert et al., 2004;), pregnancy (Fredriksen et al., 2008), and cancer (Gooden \& Winefield, 2007) and rarer diseases, such as Huntington's disease and primary biliary cirrhosis (Coulson et al., 2007; Lasker et al., 2005). While this approach is helpful in exploring how an established discussion forum operates, the topics that are discussed, and the different ways individual users navigate the forum, it does not allow exploration of how the character of the forum is shaped by its users during the very early days of its existence, and how issues of identity and authority are established.

In this paper we explore precisely these issues by presenting data drawn from a purpose-built discussion board only available to known participants within a research project as part of a broader pilot study of an internet-based diabetes self-management tool. We demonstrate how the identity of the community was established early on by its users, and how this acted to shape the kinds of interactions and discussions that took place thereafter. We also discuss the important ways in which individuals sought to establish themselves as reliable and authoritative sources of information.

\section{Methods}

The data presented in this article were collected as part of a wider programme to develop and pilot the Virtual Clinic internet-based self-management system for diabetes (author citation). This work consisted of three main stages: (i) a detailed consultation with a variety of stakeholder groups, including patients and relevant health professionals; (ii) a hands-on pre-test session with patients, followed by a focus group 
to elicit their views; and (iii) a 6-month pilot study. This paper is based on data collected during the pilot study phase.

\section{Participants}

The study was reviewed and given a favourable opinion by the West Midlands Multicentre Research Ethics Committee. The particular group of patients we worked with were adults who all used insulin pumps providing continuous subcutaneous insulin infusion to manage their Type 1 diabetes. Participants were recruited by convenience sampling, as is appropriate for pilot or exploratory work (Green and Thorogood, 2004), from three UK hospitals in the West and East Midlands. Health professionals within the three study sites issued recruitment packs to all eligible patients in their clinics. The recruitment pack contained a letter inviting patients to participate and an information sheet outlining the research and what participation would involve. All the participants were over 18 years of age, had used an insulin pump for at least 6 months, could communicate effectively in written and spoken English (we had no resources for translation), had internet access, and reported they possessed basic computer literacy skills. Patients were informed that participation was voluntary and that refusing participation or withdrawing from the study at any time would not affect the standard of care they received.

The study involved 17 patients who used the Virtual Clinic over a period of six months. The study sample consisted of six males and 11 females and the age range of participants was 22 to 70 years. All participants reported themselves as being of white British ethnicity, with eight being educated to undergraduate level or above. All participants described themselves as regular users of the internet, with 11 reporting daily use, and most reporting using it more than once a week. On average, respondents reported using the internet for 8.9 hours a week. 


\section{The forum}

The Virtual Clinic tool had three main features: (i) secure messaging between patients and their health professionals; (ii) relevant links to further internet-based information and support; and (iii) asynchronous peer-to-peer discussion board, from which the data presented in this paper are drawn. The Virtual Clinic was password-protected and only available to the participants involved and those working directly on the study. Participants in the pilot study were asked to log-in to the Virtual Clinic at least once a week, but were free to use the features within it as much or as little as they wished. Data from the discussion board were captured on a weekly basis throughout the sixmonth pilot study.

The discussion board was not anticipatorily moderated; each message posted appeared without prior scrutiny. A system of reactive moderation was used in which the discussion board was regularly reviewed by the research team, and participants were encouraged to report postings they regarded as problematic. No such reports were made and review by the research team did not identify any problems. As a result no postings were amended or deleted during the study.

The suggestion that participants use the Virtual Clinic's features as much or as little as they wished and the reactive approach to moderation adopted, together mean that the 'social design' of the discussion board (Bar-Lev, 2008) was very light touch. This approach, in particular the lack of formal guidelines for usage, may have influenced the way in which the community developed and played a role in establishing the overall social atmosphere.

\section{Analytic approach}


We use thematic discourse analysis (Potter and Wetherell, 1987; Braun and Clarke, 2006) to apply insights from discursive psychology (Edwards, 1997) to the thematic categories identified in the online accounts. A distinct feature of thematic discourse analysis is the focus on both the rhetorical composition of themes and the accompanying assumptions (Peel et al, 2005). According to Potter and Wetherell (1987) the approach consists of two phases: a search for patterns in the data followed by analysis of the function or purpose of the identified themes. This process represents the 'latent' as opposed to the 'semantic' approach to analysis in that it 'goes beyond the semantic content of the data, and starts to identify or examine the underlying ideas, assumptions, and conceptualizations -- and ideologies -- that are theorized as shaping or informing the semantic content of the data' (Braun and Clarke, 2006: 84, original emphasis). The approach has been adopted in various studies of health and illness discourses (Singer and Hunter, 1999; Peel et al, 2005), and has also proved useful in online social research (Walstrom, 2004).

In this study, thematic analysis of the discussion board postings was based upon the constant comparative method (Glaser and Strauss, 1967). Each message was read 34 times and open codes initially applied line-by-line in order to represent the meaning or significance of each sentence or group of sentences. The open codes were then incrementally grouped into organising categories or themes. These categories were then modified and checked constantly as further open codes were incorporated. The categories and their specifications (the coding scheme) were then programmed into the NVivo qualitative software. The coding scheme was used to process the dataset systematically by assigning each section of text to a category, according to the category specifications. The identified categories served as primary lenses for our analysis of identity construction through such socio-interactional business as establishing legitimacy and displaying competence (Edwards, 1997). We then turned to 


\section{1}

discursive psychology to identify and describe the latter processes, as this approach enables a detailed examination of identity construction through the lens of 'accountability work' (Potter and Wetherell, 1987). In this way, discursive psychology allowed us to deepen our analytical understanding of the legitimating and supportive functions of participants' exchanges, indexed in the structural features identified via the constant comparison method.

In following the discursive psychology approach, we examined how participants created legitimacy and authority within the broader rhetorical and interactional processes of eliciting, giving, and receiving practical advice and emotional support (Harrison and Barlow, 2009). Such a non-cognitivist approach treats identities as social phenomena; when people describe events, 'they attend to accountability. That is to say, they attend to events in terms of what is normal, expectable and proper (Edwards, 1997: 7). Participants' replies (or next turns) were used for validating our interpretation of an initial post/question (Seale, 1999). However, unlike previous analyses of interaction in long-standing, well-established online fora, we did not focus on individual narratives per se but instead attempted to explore how the discursive management of participants' identities might have contributed to, and have been influenced by the emergence and maintenance of the group's collective identity. Here the classification of features characterising an online group as a community, namely identity, sociability and support, is particularly apposite (see Herring, 2004). Active participation and continuous interaction of its members (sociability) allows an online group to develop shared norms and values as well as create an awareness of its distinguishing features (identity). By demonstrating solidarity and reciprocity and following any existing as well as emerging social participation guidelines, members can then maintain the group (support) (Herring, 2004). From this perspective, online discursive community is seen 
as first and foremost a 'mutable construct, determined by social actors who create meaning about it' (Fernback, 2007: 66).

\section{Findings}

\section{Topics discussed}

The discussion board was active throughout the six months of the pilot study, although usage as a whole gradually declined over this period. In total, 34 distinct discussion threads (by which we mean a series of related communications on a particular topic) were created with a total of 219 individual messages posted across these. The discussion board emerged as the most valued feature based on both qualitative and quantitative user feedback (author citations).

The issues discussed centred around three core areas. Firstly, and as to be expected, there was a substantial focus on issues related to diabetes self-management. These discussions tended to revolve around the challenges faced by participants in achieving and maintaining good control of their blood glucose. Blood glucose levels featured prominently as an indicator of control in many of the messages posted as participants reported unexpectedly high or low levels and described (sometimes at length) their attempts to understand the symptoms they were experiencing and regain some feeling of control (Charmaz, 2000). Secondly, participants were also keen to receive information about and discuss new possibilities or future treatments. These could be new developments per se (such as possible new treatment options or medical advances that might be on the horizon), or simply things they had not yet experienced themselves to date. In the latter case, participants were particularly keen to hear from other users who may have had diabetes for a longer period or have experienced complications that they themselves could see approaching. Thirdly, a distinct group of threads involved coping psychologically with diabetes, for example sharing and 

1

exchanging ideas about how to 'look on the bright side' and see the possible 'silver linings' of the condition.

\title{
Developing the community's identity and boundaries
}

Diabetes-focused, with no space for purely social interaction

There was a relatively clear distinction between a small minority of, typically younger, participants who initially appeared to want the discussion board to act as a general social interaction space and the majority who were simply concerned with discussing diabetes-related issues. Those that fell into the former group created and participated in a small number of discussion threads in the very early days that were designed specifically to find out more about others as individuals rather than just as people who had diabetes. However, these were often not replied to and stopped appearing as the days and weeks passed. In contrast, frequent postings on practical issues of diabetes management received positive appraisal:

\section{RE: Welcome to the Virtual Clinic!}

What a lot of activity since I last logged on. All very useful info and views.

(Participant 1, male)

\begin{abstract}
Although emotional support was also acknowledged, the most common way of expressing gratitude was to thank other participants for their 'informative' replies.
\end{abstract}

As a result, the discussions that took place within the community came to focus solely on diabetes-related issues.

\section{Creating and maintaining solidarity and support}

Although active social interaction was implicitly discouraged, participants developed different ways of eliciting social information during their diabetes-specific interaction, 
which allowed them to conform to the unspoken rule of prioritising informational exchange. One member, for example, posted a series of diabetes specific questions followed by a question about the name of one's pump:

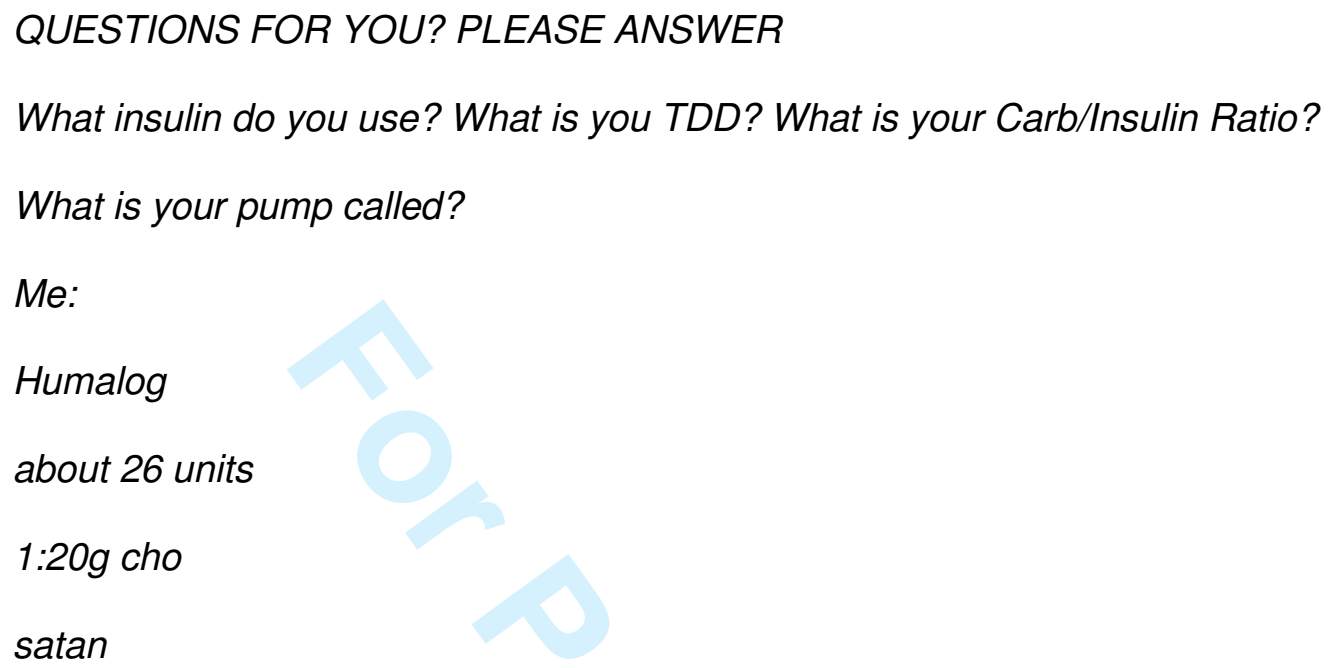
same strategy of mixing diabetes-specific information with more personal disclosures.

As posts increased in number, participants started to use different interactional resources to construct their experience as 'shareable', such as making oblique references to comparable experiences and prior speakers.

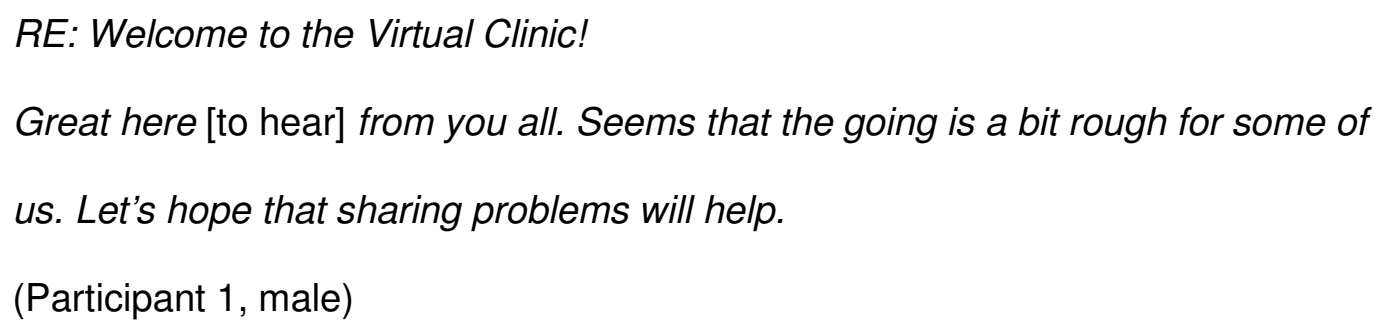


This, in turn, may have gradually contributed to creating and strengthening the group's solidarity. For example, the following comment begins with an appreciation of a previous participant's story, and proceeds to stress the benefits of participation for 'the newcomers':

\author{
RE: The Weather \\ What can I say except that your diabetic history, problems, hopes and aspirations \\ (the read and adjust gadget, when it comes) sound just like mine. [...] Hopefully \\ the newcomers will benefit by getting advice that no-one else can give them, \\ except people who've been there, done it, and got the hospital gowns. (20 years \\ ago) and the pump (now). \\ (Participant 9, male)
}

Participants also repeatedly emphasized the reciprocity of mutual help, which allowed them both to express their gratitude and demonstrate their own contribution in assisting others. This rhetorical work, referred to as 'the rhetoric of gratitude' (Arminen, 2001), seemed to have functioned as an important social glue that might have facilitated participation in this community from its inception onwards. One of the indicators pointing to this effect was an increase of newcomers who might have 'lurked' for some time on the forum trying to learn the local interactional ropes before deciding to contribute. Approximately a month after the start of the group, both existing and new members began to post more personal questions that can be seen as potentially compromising their identity as 'sensible' or rational individuals. The following question about having children with diabetes is an example:

\title{
Diabetes and Pregnancy
}




\author{
Hello. .. . Ok! This has taken some gutts to start this, but i've got sooooo many \\ questions that I would love answers to but always clam up when I start asking \\ them when I go to clinic. So ... I'm hoping people on here can give me some \\ answers etc. [...] Ok... here goes (congratulate me on my bravery) \\ (Participant 16, female)
}

The above post contains a number of hedging devices used to demonstrate the author's feelings of insecurity about participation and expectations of this group. Although we have no direct evidence, it may be plausible that earlier discussions on this site made the person feel safe (Mitra, 2006) as they had been observing the spirit of 'togetherness' and good natured expressions of mutual support and respect.

Overall, through references to shared experiences and the rhetoric of gratitude this discussion forum started to function as an interactional mechanism for enabling and fostering the exchange of practical information and support. As one of the participants stated in his 'goodbye' post: 'I think the beauty of this forum has been to remind us that we're not on our own. Don't ever give up!'

\title{
Testing the limits
}

One of biggest rhetorical challenges faced by people who consider participating in an online group is demonstrating their legitimacy - that their discursive contributions are genuine and valid. Other studies have shown that when joining a long established online forum participants draw on their history of disease, past experiences, and/or tailor their posts to the most discussed topics to legitimate their claim for the group's attention (Gallagher et al, 1998). In this study we had an opportunity to examine how, in the absence of prior discussions, the very first posts served simultaneously to create legitimacy and test the limits of what can or cannot be discussed. In his first post, one 
participant starts by outlining his medical history to legitimate his contribution to this diabetes-focused forum.

\author{
RE: Welcome to the Virtual Clinic! \\ I am 59 years old and have been brittle insulin dependent type 1 diabetic for 29 \\ years. I have always, with great effort, managed to get good HBA results but, \\ being averages, the HBA results do not show the often wild blood sugar \\ fluctuations I suffered before using an insulin pump. To clarify, BG readings of \\ $2 \mathrm{~mm}$ and $11 \mathrm{~mm}$ are obviously bad news, and yet they give an "average" of \\ $6.5 \mathrm{~mm}$, often described to me as "excellent". One could only wish that the \\ Doctors concerned could try out this "excellence" for themselves.
} (Participant 9, male)

With the help of this story the participant presents himself as a person who, despite the difficulties, is able to manage his condition ('with great effort, managed to get good $H B A$ results'). After undermining potential assumptions regarding a lack of competence in interpreting $B G$ readings ('2 $2 \mathrm{~mm}$ and $11 \mathrm{~mm}$ are obviously bad news'), the participant proceeds to introduce a thinly veiled criticism of 'the Doctors'.

This reference to prior interaction with medical authorities was quickly picked up and expanded upon by other members on this 'introductory' thread:

\title{
RE: Welcome to the Virtual Clinic!
}

I sometimes wonder whether the experts have got their lines crossed as some will tell you that the peaks and troughs are all important, others that it is only the 3 monthly HbA1c that is significant. How can anyone avoid the ups and downs, I ask? 
(Participant 1, male)

In some cases, participants involved in posting what they were aware were likely to be seen as 'unorthodox' views or behaviours took steps to actively draw attention to this and questioned whether it was suitable for discussion within the community. In the following example, after the original posting, another member of the community responded to sanction or legitimise the view expressed in the original message, and to encourage the further free expression of views:

\section{RE: Welcome to the Virtual Clinic!}

I managed to keep blood sugars between 4 - 8 by testing my sugar about 14 times per day, even twice at night and ate next to nothing. Very low carb meals. yeah, EXCELLENT control but NO LIFE.... that's just not cool. So it can be done, but it's boooooring. It's ideal though, go low carb about a month b4 your HBA1C and hurrah, good result and no telling off from your doc!! *oh dear, should I really be saying that on here????*

(Participant 13, female)

RE: Welcome to the Virtual Clinic!

You should say EVERYTHING on here, perhaps if enough of us shout then maybe people will listen...SO KEEP SHOUTING - let's all make a noise. (Participant 9, male)

As the community developed over time, the limits on what points of view could be expressed began to be tested, established and policed. One of the most obvious examples concerned whether participants were 'allowed' to identify themselves as not always strictly following prescribed courses of action in relation to their diabetes selfmanagement. Common examples of this concerned individuals' personal admissions 
of knowingly not always doing the 'right thing', which is a way of attending to accountability by carefully balancing the presentation of 'deviant' cases and their justifications. The following is a typical example of this:

\author{
$R E:$ End of cartridge highs \\ Thank God I'm not alone and other people are pretty 'naughty' on not changing \\ cannulas as often as we should. When it's in a comfortable spot it's such a bitch \\ to think of changing it. I usually go 3/4 days to be honest but I know for a fact that \\ on some sites (usually where it's been uncomfortable from the start) it definitely \\ affects the rate at which the insulin's absorbed. I think your problem could be \\ changing the cannula more often. \\ (Participant 12, female)
}

Here the participant demonstrates her awareness that the first sentence of her post is potentially controversial as it refers to the transgression of established norms. She therefore proceeds to account for the lapse (2nd sentence). The final two sentences function to present the participant as someone knowledgeable and in control as well as enable the provision of indirect advice. Below we will explore this strategic use of personal stories in more detail,

\title{
Doing identity work within established boundaries
}

It was particularly interesting to study how the interconnected processes of identity building and advice giving proceeded in this newly established community, where 'everything should be said' despite the awareness that their talk will be studied by researchers. 
Perhaps in adhering to the earlier assertion that the forum is a legitimate place for expressing 'unorthodox' views, some of which involved blaming 'professionals' or questioning and contradicting medical advice, some participants contrasted their experiential knowledge and/or professional experience with biomedical expertise. The following example relates to a post concerning the effect of diabetes on pregnancy:

\section{Diabetes and Pregnancy}

Firstly, I'm in no rush to have children (but) my ultimate worry is diabetes affecting my ability to have 'healthy' babies, and the complications that I will incur etc etc. It's all the things you read, like if you plan to have a baby you must tell your specialist a few months before to get stable sugars, and then during the first few weeks your blood will go mad and you have to keep it stable. Then there's the bit about the baby getting really big, and recently there was something about babies being born having a dependency on insulin. Also years ago a nurse told me I would never be able to give birth I would have to have a c section . . I've just got sooo many questions and I just need anyone who has either gone through it, or knows any words of wisdom to put my little mind at rest.

Thank you (phew)

(Participant 16, female)

RE: Diabetes and Pregnancy

Hi, just some input on this cos I have my own child and I work in a special care baby unit so see a lot of babies from IDDM (Insulin-Dependent Diabetes Mellitus) mothers. I found that the first 2 months of pregnancy were the worst and I couldn't believe how unstable and fragile I was, after that things just kinda fell into place and all went well until 35wks when I delivered [child], normally. Healthy and well. From a prof point the things to keep in mind are that the more stable your BGs are the less likely you will have problems. Diabetics always have 
bigger babies and it's no good keeping your BGs too low cos this can lead to problems with the baby. The other thing is when you do go into labour make sure you get to hospital ASAP as this can be the most dangerous time in any pregnancy esp when you are IDDM.

(Participant 15, female)

Here Participant 16 is explicitly interested in hearing from others who have 'gone through it' and in this way is seeking descriptive accounts rather than direct advice and evaluation ('what was your experience?' rather than 'Is this the right thing to do?). In response to such an interactional environment, participant 15 carefully manages her response by using a softener ('just some input on this') followed by a short story drawing on her own experience as a mother but additionally highlighting her experience of working on a special care baby unit (although she does not specify in what capacity). In addition to functioning as a politeness strategy of demonstrating empathy and enabling indirect advice giving, the short one-sentence story ('I found that...') also helps to construct the participant as experientially knowledgeable. The participant then switches from personal to professional source of expertise using the phrase 'from a prof point of view' to bring in the biomedical discourse and accompanying factual references ('diabetics always have bigger babies').

A small number of users presented themselves as authoritative and knowledgeable through references to their activity and research in the area of diabetes, and by emphasizing that they went to great lengths to keep themselves well-informed and upto-date with medical knowledge and new developments. They were frequently keen to share this knowledge with others and typically had their input, judgement and evaluations accepted and valued by others. The extract that follows, in which one 
participant asks for (and receives) feedback on the demonstration of a new piece of equipment, is an excellent example:

\author{
Continual Monitoring Pump \\ Does anyone have any feedback on the continuous monitoring pump that was \\ demonstrated at [Hospital Name] a couple of weeks ago. I couldn't make the \\ meeting and am intrigued to have an update and opinions.
}

(Participant 12, female)

RE: Continual Monitoring Pump

The Continuous monitoring pump was the [product name], see [weblink]. However, also see [weblink] and notice the difference between UK and US [product] prices, about $4 x$ as much. Note that the unit has to be calibrated (with ordinary BG tests) twice a day and 'no $\mathrm{CHO}$ or insulin action should be taken without BG test verification' which seems to make the whole thing a waste of time. It is, however, the cost of sensors which kicks the whole thing into touch...Also independent tests at Diabetes Mail confirm that it ain't very accurate, see [weblink] Oh well, maybe in the future...

(Participant 9, male)

RE: Continual Monitoring Pump

Cheers [name]. Don't think I'll even bother taking a look on the website. I thought we were getting a little closer to a pump that measured BGs and reacted accordingly. Do I dream or what!!!!!

(Participant 12, female)

In this case, Participant 9 demonstrates his expertise by drawing on a range of sources to support his assessment of the situation. Participant 12 is apparently so persuaded by the assessment of the new technology that Participant 9 has provided she does not 
feel the need to undertake any further research on the topic herself even though he has provided her with links to the websites to which he has referred.

\begin{abstract}
A final, but less common, strategy was for a participant to claim some form of professional recognition for a perspective that they had developed and advanced. The following extract is a particularly powerful example in which one individual describes how he had noticed a correlation between episodes of severe hypoglycaemia (low blood glucose) or 'hypos' and sudden and severe drops in the temperature.
\end{abstract}

\begin{abstract}
RE: The Weather
29 years ago when I first became unstable diabetic, trying to stay upright was far more difficult, as there were no home blood-testing kits and severe hypos were thus far more frequent. After the first 3 A\&E visits (in as many weeks) I couldn't understand what I had done wrong, having stuck religiously to what 'rules' there were. Then I suddenly realised that the common denominator was sudden and severe drops in temperature, which had happened immediately before each incident. I told the 'professionals' about this but they all humoured me and clearly thought I was talking rubbish and making lame excuses for carelessness.

Recently, the 'temperature factor' has been officially recognised, and is written in text-books. The same 'professionals' give you the same advice (now scientifically smothered) that you originally gave them, in plain English, a long time before.... (Participant 9, male)
\end{abstract}

Participant 9 states that, whilst he felt that health professionals had humoured him at the time rather than taking his idea seriously, medical text books were now beginning to include this information, thereby endorsing the idea that he had advanced sometime earlier. The telling of this story works to construct this participant as someone who is 
actually 'ahead of the game' and with whom the professional community will eventually 'catch-up'. This strategy might be particularly effective with other participants who feel that their health professionals are not taking their ideas or experiences seriously.

\section{Going too far}

As explained earlier, we adopted a reactive approach to moderation, meaning that all messages posted were immediately visible without prior scrutiny. Instead, we regularly reviewed content, and participants were encouraged to notify us of any messages they regarded as problematic. No messages were brought to our attention during the study. In fact, on the rare occasions that a particular comment was perceived by participants as inappropriate or as having 'gone too far', it was quickly dealt with by either themselves or other participants. This is demonstrated in the following example, in which one user's advice to adopt a particular weight loss strategy (cutting down on the amount of insulin taken) is quickly problematised and highlighted as dangerous by another user:

\section{Losing weight}

Next of my questions... has anyone got any hints on how to lose weight? I don't eat loads, I eat healthy food and I go to the gym, however it won't shift. When I asked the doctor about this, he said I was unlikely to lose weight, but need to be careful not to put any on as I won't lose it. I'm not big, l'm a size 12, but l'd like to get rid of some wobbly bits........any ideas anyone?

(Participant 16, female)

RE: Losing weight

Of course, cut back your insulin.

(Participant 13, female)

RE: Losing weight 


\author{
But my sugar levels are fine... and cutting back will make me high \\ (Participant 16, female) \\ $R E$ : Losing weight \\ I was worried to see someone suggest running high bloods to lose weight \\ though, don't do it! It's really dangerous! \\ (Participant 18, female)
}

Other research exploring discussions taking place within health-related internet-based fora has shown that, whilst most information posted by participants is accurate, that which is not is very quickly corrected or challenged by other users (Esquivel et al., 2006). We can see that the community, through its individual members, came to actively negotiate and enforce the boundaries surrounding what could and could not be expressed. As a result the community came to develop a particular identity.

\title{
Discussion
}

Our study showed that a small number of motivated users who shared specific health characteristics (having type 1 diabetes and using insulin pumps) who were recruited to a closed internet forum participated in focussed discussions over a sustained period of time. The main topics discussed related to self-management of blood glucose levels, information on new treatments, and illness coping strategies, therefore indicating the formation of a task-oriented group. This is not surprising given the clear parameters under which the community was constructed and the individual participants recruited.

As has been found in other online support groups, user empowerment can be fostered through the sharing of information (Fox et al., 2005; Coulson, 2005), and the promotion of self-confidence and feelings of independence and control (van Uden-Kraan et al., 2009; Lemire et al., 2008). This is especially important in long-term conditions such as 
diabetes where self-efficacy (the belief that one has the capabilities to execute the courses of action required to manage prospective situations) has been shown to have a positive relationship with successful self-management and better health outcomes (Brownson et al., 2009). Indeed, studies of other internet-based diabetes communities have shown positive effects on self-management (for example, Rasmussen et al., 2007).

Health-related internet communities are clearly subject to the social psychological processes present in all groups, as well as those more specifically found in online settings (Bargh \& McKenna, 2004). For example, normative social influence and intragroup conformity occurs online, even in anonymous settings (Sassenberg \& Jonas, 2007). We were particularly interested in how, in a new community, issues of identity and authority were interactively managed. Participants used brief stories to make indirect suggestions, which also served to demonstrate shared concerns and experiences as well as authority. This supports the findings of Harrison and Barlow (2009:94) who showed how the use of short narratives in online support fora can "simultaneously (1) function as a positive politeness strategy demonstrating empathy, (2) enable participants to give advice indirectly, and (3) help to construct participants' identities as expert patients". Furthermore, by demonstrating how the participants were constructing legitimacy and authority through online talk, this study resonates with recent ethnographic research that aims to develop a nuanced understanding on online socialities (Kozinets, 2010). This stream of research disputes earlier assertions by social psychologists that online communications would be characterised by a reduction of social cues and flattening of hierarchies (Dubrovsky et al, 1991).

In line with the tenet that online group norms are not static but develop over time and change in relation to local discursive contexts (Walstrom, 2004) we have also paid 


\section{1}

attention to the temporal aspects of the online interaction. The identity of the community as a space for focussed discussion of diabetes, rather than for any broader social interaction, was established quickly during the first two months and the boundaries of this, when tested, were soon reinforced and continued to be maintained until the end of the six month period. No hostile behaviour was noted and misinformation was quickly corrected. We can only speculate about the reasons for this lack of interest in the Virtual Clinic acting as a forum for more general social interaction. It would seem likely though that, given participants valued the discussion board precisely for the way it allowed them to be in touch with other people with diabetes, they would not want this focus to be diverted or diluted by more general social interaction which they could (perhaps) easily gain elsewhere.

Although the online community under study did not demonstrate a high level of commitment and interpersonal interaction observed in other, mostly non-supportoriented online fora (e.g. Ley, 2007), this did not prevent it from establishing itself as an efficient instrumental grouping where participants were able to share highly targeted practical advice as well as emotional support. It is possible that such social architectural features as reactive moderation and open-ended, non-prescriptive participation guidelines have encouraged participation and affected the nature of discursive contributions by providing a relatively secure space for the exchange of views and advice. As a result, participants successfully co-constructed their group identity through shared understandings of "behaviours and meanings within a collective realm of action' (Fernback, 2007: 66).

These findings are resonant with the research conducted on face-to-face groups (Arminen, 2004) and found that "the organization of AA members' experiences cannot be located in individual turns or within individual's talk and cognitive processes. Rather, 
AA meetings are a seamless web of interconnected turns in which speakers build their turns as new contributions to the context provided by previous turns" (2004: 323). From this perspective, the rhetorical and interactional dynamics of online support groups, such as the one investigated here, call for a further in-depth study of group-level phenomena that cannot be directly attributed to individual discursive acts.

\section{Limitations}

Due to its nature as a local, pilot study the project only has a small sample and the inclusion criteria were relatively tight. The sample was relatively diverse in terms of age and educational level, but as it was drawn on the basis of convenience we cannot claim to have a representative sample and other groups of participants may have interacted differently. In addition, a small number of participants appear more than once throughout our presentation of the findings. While we have tried to avoid this where possible, it has sometimes been necessary for example due to their key role in shaping the discussion forum. The fact that the discussion forum operated only as part of a wider study of an internet-based self-management tool means that we would perhaps expect the focus of discussions to be self-management and for this to be prioritised over more general social interaction. It is also possible that knowing they were part of a research study influenced the way participants used the discussion forum, although in subsequent interviews participants reported using the discussion forum as they would other non-study related fora (author citation). Participants were aware that the pilot study would only be for six months' duration and it is possible that this knowledge influenced the way in which the identity and authority of both the group and its individual members were established.

\section{Conclusion}


Internet communities can have a valuable role in engaging people with long-term conditions such as diabetes in issues that affect their health and health care. Internet discussion fora are shaped in important ways early on by the community of users. If promoting self-efficacy is the key to effective self-management, then peer-to-peer communication is a promising area and has the advantages of being low (or indeed no) cost and highly acceptable to patients. However, there is a clear need to be aware of the social processes that shape online communities. In order to harness the potential benefits, health services need to acquire a multi-faceted understanding of the social processes that occur in online communities, including how the character and focus of the discussion is formed over time, and how both information and individual users can be constructed as authoritative and reliable. Health practitioners should note that such communities can have clear empowering benefits and at the same time that concerns about the propagation of inaccurate or misleading information are not supported by our findings. Future research should consider the influences of participant authority and identity on the health behaviour of participants in internet communities. 


\section{References}

Arminen, I. (2001). Closing of turns in the meetings of Alcoholics Anonymous:

Members' methods for closing "sharing experiences". Research on Language and Social Interaction, 34, 211-52.

Arminen, I. (2004). Second stories: The salience of interpersonal communication for mutual help in Alcoholics Anonymous. Journal of Pragmatics, 36, 319-47.

Bargh, JA., and McKenna, KYA. (2004), The internet and social life. Annual Review of Psychology, 55: 573-90.

Bar-Lev, S. (2008). "We are here to give you emotional support": Performing emotions in an online HIV/AIDS support group. Qualitative Health Research, 18, 509-521.

Braun, V., and Clarke, V. (2006). Using thematic analysis in psychology. Qualitative. Research in Psychology, 3, 77-101.

Brownson, CA., Hoerger, TJ., Fisher, EB., and Kilpatrick, KE. (2009). Costeffectiveness of diabetes self-management programs in community primary care settings. Diabetes Educator, 35, 761-9.

Burnett, G. and Buerkle, H. (2004). Information exchange in virtual communities: a comparative study. Journal of Computer Mediated Communication, 9(2).

Charmaz, K. (2000). Experiencing chronic illness. In G. Albrecht, R. Fitzpatrick, and SC. Scrimshaw (Eds.) pp.277-92, The handbook of social studies in health and medicine. London: Sage. 
Chen, YC., and Li, IC. (2009). Effectiveness of interventions using empowerment concept for patients with chronic disease: a systematic review. Journal of Advanced Nursing, 66, 1446-1451.

Costa, BM., Fitzgerald, KJ., Jones, KM., and Dunning, AMT. (2009). Effectiveness of IT-based diabetes management interventions: a review of the literature. BMC Family Practice, 10,72 .

Coulson, N. (2005). Receiving social support online: an analysis of a computermediated support group for individuals living with irritable bowel syndrome.

CyberPsychology and Behavior, 8, 580-4.

Coulson, NS., Buchanan, H., and Aubeeluck, A. (2007). Social support in cyberspace: a content analysis of communication within a Huntington's disease online support group. Patient Education and Counselling, 68,173-8.

Department of Health. (2007). Supporting People with Long Term Conditions. London: Department of Health.

Diabetes UK (2011) http://www.diabetes.org.uk/Guide-to-diabetes/Introduction-todiabetes/What_is_diabetes/

Dubrovsky, V., Kiesler, S. \& Sethna, B. (1991). The equalization phenomenon: Status effects in computer-mediated and face-to-face decision making groups. HumanComputer Interaction, 6, 119-146. 
Edwards, D. (1997). Discourse and cognition. London: SAGE.

Esquivel, A., Meric-Bernstam, F., and Bernstam, EV. (2006) Accuracy and self correction of information received from an internet breast cancer list: content analysis. British Medical Journal, 332, 939-942.

Fernback, J. (2007). Beyond the diluted community concept: A symbolic interactionist perspective on online social relations. New Media \& Society, 9, 49-69.

Fox, N., and Ward, K. (2006), Health identities: from expert patient to resisting consumer. Health, 10:461-79.

Fox, NJ., Ward, KJ., and O'Rourke, AJ. (2005). The 'expert patient': empowerment or medical dominance? The case of weight loss, pharmaceutical drugs and the Internet. Social Science and Medicine, 60,1299-1309.

Fredriksen, EH., Moland, KM., and Sundby, J. (2008). 'Listen to your body'. a qualitative text analysis of internet discussions related to pregnancy health and pelvic girdle pain in pregnancy. Patient Education and Counselling, 73:294-9.

Galagher, J., Sproull, L., and Kiesler, S. (1998). Legitimacy, authority, and community in electronic support groups. Written Communication, 15:493-530.

Glaser, B., and Strauss A. (1967). The discovery of grounded theory. Chicago: Aldine. 
Gooden, RJ., and Winefield, HR. (2007). Breast and prostate cancer online discussion boards: a thematic analysis of gender differences and similarities. Journal of Health Psychology, 12,103-114.

Green, J., and Thorogood, N. (2004). Qualitative methods for health research. London: Sage.

Hardey, M. (1999). Doctor in the house: the Internet as a source of lay health knowledge and the challenge to expertise. Sociology of Health and IIIness, 21,820-35.

Harrison, S., and Barlow, J. (2009). Politeness strategies and advice-giving in an online arthritis workshop. Journal of Politeness Research: Language, Behavior, Culture, 5, 93-111. Heisler M, Vijan S, Makki F, and Piette JD. (2010). Diabetes control with reciprocal peer support versus nurse care management. A randomized trial. Annals of Internal Medicine, 153,507-15.

Herring, S. (2004). Computer-mediated discourse analysis: An approach to researching online behaviour. In SA. Barab, R. Kling, and JH. Gray (Eds.), pp.338-76, Designing for virtual communities in the service of learning. New York: Cambridge University Press.

Holman, H., and Lorig, K. (2004). Patient self-management: a key to effectiveness and efficiency in care of chronic disease. Public Health Reports, 119, 239-243.

Kozinets, R. (2010). Netnography: Doing ethnographic research online. London: Sage. 
Kummervold, PE., Chronaki, CE., Lausen, B., Prokosch, H., Rasmussen, J., Santana, S., Staniszewski, A., and Wangberg, SC. (2008). eHealth trends in Europe 2005-2007: a population-based survey. Journal of Medical Internet Research, 10:e42.

Lasker, JN., Sogolow, ED., and Sharim, RR. (2005). The role of an online community for people with a rare disease: content analysis of messages posted on a primary biliary cirrhosis mailing list. Journal of Medical Internet Research, 7,e10.

Lemire, M., Sicotte, C., and Paré, G. (2008) Internet use and the logics of personal empowerment in health. Health Policy, 88,130-40.

Ley, B. (2007). Vive les roses!: The architecture of commitment in an online pregnancy and mothering group. Journal of Computer-Mediated Communication, 12(4).

Mitra, A. (2006). Toward finding a cybernetic safe place: Illustrations from people of Indian origin. New Media and Society, 8, 251-268.

Nettleton, S., Burrows, R., and O'Malley, L. (2005). The mundane realities of the everyday lay use of the internet for health, and their consequences for media convergence. Sociology of Health and IIIness, 27,972-92.

Office of National Statistics survey http://www.statistics.gov.uk/pdfdir/iahi0809.pdf Pearson, ML., Mattke, S., Shaw, R., Ridgely, MS., and Wiseman, SH. (2007) Patient Self-Management Support. Programs: An Evaluation. Final Contract Report (Prepared by RAND for: Agency for Healthcare Research and Quality U.S. Department of Health and Human Services, November 2007) 
Peel, E., Parry, O., Douglas, M., and Lawton, J. (2005). Taking the biscuit? A discursive approach to managing diet in type 2 diabetes. Journal of Health Psychology, 10, 779-91.

Pew Internet and American Life Project. (2010) Internet, broadband, and cell phone statistics.

http://www.pewinternet.com/ /media/Files/Reports/2010/IntPIP December09 update.p df

Piette, JD. (2007). Interactive behavior change technology to support diabetes selfmanagement: where do we stand? Diabetes Care, 30:2425-2432.

Potter, J., and Wetherell, M. (1987). Discourse and psychology: Beyond attitudes and behavior. London: Open University Press.

Powell, J., and Clarke, A. (2006). Information in mental health: qualitative study of mental health service users. Health Expectations, 9,359-65.

Rasmussen, B., Dunning, P., and O'Connell, B. (2007) Young women with diabetes: using Internet communication to create stability during life transitions. Journal of Clinical Nursing, 16,17-24.

Ravert, RD., Hancock. MD., and Ingersoll, GM. (2004). Online forum messages posted by adolescents with type 1 diabetes. Diabetes Educator, 30,827-34. 
Sandaunet, A. (2008). The challenge of fitting in: non-participation and withdrawal from an online self-help group for breast cancer patients. Sociology of Health and IIIness, $30,131-44$.

Sassenberg, K., and Jonas, KJ. (2007). Attitude change and social influence on the net. In AN. Joinson, KYA. McKenna, T. Postmes, and U-D. Reips (Eds.) pp.273-88, Oxford handbook of internet psychology. Oxford: Oxford University Press.

Schaffer, R., Kuczynski, K., and Skinner, D. (2008). Producing genetic knowledge and citizenship through the Internet: mothers, pediatric genetics and cybermedicine. Sociology of Health and IIIness, 30,145-59.

Seale, C. (1999).The quality of qualitative research. London: Sage.

Singer, D., and Hunter, M. (1999) The experience of premature menopause: a thematic discourse analysis. Journal of Reproductive and Infant Psychology, 17, 63-81. van Uden-Kraan, CF., Drossaert, CHC., Taal, E., Seydel, ER., and van de Laar, MAFJ. (2009). Participation in online patient support groups endorses patients' empowerment. Patient Education and Counselling, 74,61-9.

Walstrom, M. (2004). 'Seeing and sensing' online interaction: An interpretive interactionist approach to USENET support group research. In MD. Johns, CC. Chen, GJ. Hall (Eds.) pp.81-97, Online social research. Methods. issues and ethics. New York : Peter Lang. 
Welch, G., and Shayne, R. (2006). Interactive behavioral technologies and diabetes self-management support: recent research findings from clinical trials. Current Diabetes Reports, 6,130-136. 